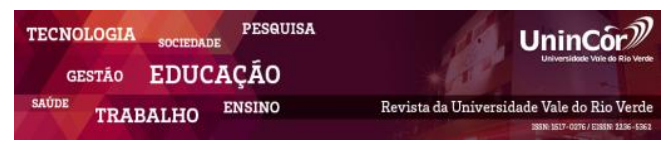

Revista da Universidade Vale do Rio Verde ISSN: 1517-0276 / EISSN: 2236-5362 v. $16 \mid$ n. 2 | Ano 2018

Maria Cláudia Cardoso de Brito Universidade Vale do Rio Verde prof.maria.brito@unincor.edu.br

Flávia Moysés Costa de Grajeda Universidade Vale do Rio Verde prof.flavia.grajeda@unincor.edu.br

Lílian Juri Rezende de Lacerda Universidade Vale do Rio Verde lilianrezendelacerda@hotmail.com

Carolina Freitas Lage Universidade Vale do Rio Verde carolina.lage@unincor.edu.br

Túlio César Modesto Universidade Vale do Rio Verde tulio.silva@unincor.edu.br

\section{O PROCESSO AVALIATIVO NO ENSINO SUPERIOR COM ÊNFASE NA ODONTOLOGIA}

\section{RESUMO}

A avaliação é um processo que faz parte do nosso dia-a-dia, avaliamos e somos avaliados constantemente, nas nossas ações e resultados, seja em casa, no trabalho ou como cidadão. No cotidiano escolar não é diferente, a avaliação é parte relevante e fundamental do processo ensino-aprendizagem, podendo assumir o papel de determinar as competências, habilidades e conhecimentos que o currículo privilegia ou deixa para segundo plano, assim como pode determinar também as estratégias e os diversos tipos de planejamentos, de aula, de projetos, de recuperação paralela e contínua, e mais que isso, dependendo dos seus resultados e das consequentes ações que ela gera, a avaliação pode ser o fator decisivo para a melhoria da qualidade de ensino nas escolas públicas. As leis do país sobre educação e as propostas curriculares atuais preocupam-se em indicar uma avaliação contínua, formativa e individualizada, tornando-a mais um elemento do processo educativo e não o fim dele. Muitas instituições escolares, tem buscado a melhoria na qualidade da avaliação, mas o que realmente se percebe, na prática, é que este trabalho é, quase sempre, emperrado pela burocracia das instituições e pela falta de preparo do professor, que é um especialista e, muitas vezes, não sabe como transformar a avaliação que aprendeu nas carteiras escolares, como aluno, numa avaliação de efetivo resultado. Assim, conhecer o processo avaliativo que acontece atualmente no ensino superior, especificamente nos cursos de Odontologia é o objetivo deste trabalho.

Palavras-chave: Avaliação. Avaliação do Ensino Superior. Avaliação em Odontologia.

\section{THE EVALUATION PROCESS IN HIGHER EDUCATION WITH EMPHASIS IN DENTISTRY}


evaluation and individualized training, making it an element of the educational process and not the end of it. Many educational institutions has sought to improve the quality of assessment, but what really realize in practice is that this work is often stalled by bureaucratic institutions and lack of preparation by the teacher, who is an expert and often do not know how to make that assessment portfolios learned in school as a student, an assessment of actual results. Thus, knowing the evaluation process currently happening in higher education, specifically on courses in dentistry is the objective of this work.

Keywords: Evaluation. Evaluation of Higher Education. Assessment in Dentistry.

Recebido em: 10/03/2018 - Aprovado em: 28/10/2018 - Disponibilizado em: 15/12/2018

\section{INTRODUÇÂO}

A avaliação de uma maneira geral, mas principalmente do aluno sempre foi foco de pesquisa e tem desafiado e estimulado os educadores, na busca de um indicador ou receita que mostre uma maneira de se entender o aprendizado do educando. Uma das definições que mais bem retrata o que vem ser a avaliação, é a apresentada por Bloom, Hastings e Madaus (1971) in Vianna (2000):

Avaliação é a coleta sistemática de evidências por meio das quais determinam-se mudanças que ocorrem nos alunos e como elas ocorreram. Inclui uma grande variedade de evidências que vão além do tradicional exame final de lápis e papel. É um sistema de controle de qualidade pelo qual pode ser determinada, em certa etapa do processo ensino-aprendizagem, a efetividade ou não do processo e, em caso negativo, que mudanças precisam ser feitas para assegurar sua efetividade antes que seja tarde. (VIANNA, 2000, p. 57)

Ao se abordar o tema de avaliação formativa ou continuada no ensino superior se entende que é possível ao professor criar instrumentos avaliativos que não classifiquem ou selecionem os alunos, mas que busquem entender e conhecer este aluno como um ser global, que seja entendido em todos os aspectos que o formam como: o afetivo, o cognitivo, o social e o motor, proporcionando a ele aprendizagens realmente significativas e funcionais, que podem ser aplicadas nos diversos contextos em que está inserido, principalmente no profissional.

A prática avaliativa é uma das formas mais eficientes de instalar ou controlar comportamentos, atitudes e crenças entre os estudantes, podendo ser positiva ou destrutiva em suas possibilidades de desenvolvimento, pelo poder que encerra e pela importância que tem como mecanismo de inclusão ou exclusão social, através das marcas burocráticas e legais impregnadas na sua utilização. (MENDES, 2005)

A partir do pressuposto de que "basta conhecer bem o assunto, para ser um professor", como muitas vezes ouvimos na Universidade; está a suposição de que, para o ensino superior, o mais importante é o domínio dos conhecimentos referentes à sua área de 
atuação: a formação didática não seria tão necessária, porque os alunos universitários - por serem adultos, por se submeterem a rigorosa seleção, e por estarem motivados pela profissionalização ao final do curso - estariam, “a priori”, preparados para aprender sozinhos. Este quadro, vem se alterando significativamente, a partir da visão crítica do ensino superior, que se desenvolveu com as várias iniciativas de avaliação institucional; estas mostraram, frequentemente, que os alunos, ao fazerem a apreciação de seus professores, ressaltam sua competência técnica e apontam sua falta de didática, o emprego excessivo, quase exclusivo, da preleção ou aula expositiva, com baixíssima participação dos alunos e métodos avaliativos pouco eficientes (DAMIS, 1996).

Cabe ao professor de todos os níveis, principalmente ao professor universitário elaborar instrumentos avaliativos que possibilitem ao aluno fazer parte do processo, tornando-o ativo e atuante no seu processo de ensino-aprendizagem, para que ele aprenda a ter compromisso com o seu conhecimento e com o mundo em que vai atuar como profissional e como pessoa.

Isto posto, este trabalho tem como objetivo verificar o que é avaliação e quais as vantagens e limitações dos métodos de avaliação empregados no Ensino Superior, com ênfase na Odontologia e justifica-se pela necessidade de se buscar novos caminhos para a avaliação do ensino superior, principalmente nos cursos de Odontologia.

\section{DESENVOLVIMENTO}

\subsection{O que é avaliação?}

Desde o início da história da humanidade fala-se em avaliação. Primeiramente ela era realizada de maneira assistemática, isto é, de maneira casual, não fazendo parte de um sistema. Mais tarde, organiza-se e passa a ser intencional e consciente. Com o desenvolvimento da sociedade ela passa a ser utilizada por diversos setores de atividades em que o homem atuava.

Ao se falar em avaliação logo se imagina que é necessário fazer uma prova, um exame e que para estes serão atribuídas notas e valores, podendo assim, ser ou não promovido. Esta associação é muito vivenciada nas escolas de todos os níveis, por causa de uma educação tradicional, onde a aprendizagem era feita através de memorização de todas as informações recebidas, o aluno não precisava pensar, apenas decorar, bastava ser passivo e receptivo às informações.

Hoje já é possível falar em uma educação baseada na psicologia genética, onde as experiências vivenciadas são importantes e ajudam no desenvolvimento motor, afetivo, cognitivo e social do aluno. De passivo, o aluno passa a ser ativo, pois ele pode participar da construção do seu conhecimento.

Avaliar é portanto, atribuir um juízo de valor sobre um processo, aferindo a qualidade do resultado alcançado. A avaliação tem sido dirigida pelo caminho da mensuração, tentando compreender o processo ensino-aprendizagem, assim, o ato de avaliar está diretamente ligado ao 
de medir os conhecimentos adquiridos ou não pelos alunos. (KRAEMER, 2005)

$\mathrm{O}$ ato de avaliar não se encerra na configuração do valor ou qualidade atribuídos ao objeto em questão. Avaliar exige uma tomada de posição favorável ou desfavorável ao objeto de avaliação, com uma consequente decisão de ação. $\mathrm{O}$ ato de avaliar implica coleta, análise e síntese de dados que configuram o objeto de avaliação, acrescido de uma atribuição de valor ou qualidade, que se processa a partir da comparação da configuração do objeto avaliado (LUCKESI, 1995).

O professor é peça chave neste quebracabeça que é o processo ensino-aprendizagem, pois é ele quem vai determinar o tipo de avaliação a ser utilizado, produzindo nos alunos reações positivas ou negativas. Com a escolha correta e adequada, o professor pode aperfeiçoar sua prática e vai ajudar o aluno a progredir em sua aprendizagem (NEVO, 1998).

No Brasil, nas duas últimas décadas, a avaliação passou a ter intensificado estudo, onde os pesquisadores procuraram fundamentar seus conhecimentos frente à realidade educacional vigente. Nas Instituições de Ensino Superior não foi diferente, pois o Ministério da Educação tem intensificado a prática da avaliação, nas mais diversas formas, sempre buscando a excelência (FERNANDES, 2005).

\subsection{Tipos de avaliação}

O conjunto de instrumentos que são capazes de quantificar a avaliação é chamado de Processo de Avaliação e ao se estudar a teoria curricular atual, vê-se a importância da avaliação como um componente intrínseco ao processo curricular, pois não é possível separar o processo de ensino do processo de avaliação. $\mathrm{O}$ discurso proclamado pelos educadores é o da utilização de uma variedade de modos e instrumentos de avaliação, sempre adequados às diferenças e à natureza das aprendizagens que se quer ensinar podendo observar a evolução global dos alunos (COLL, 2001).

Segundo Bloom (1956), as funções da avaliação são divididas em três categorias: diagnóstica, formativa ou continuada e somativa. Apesar da data em que ele fez esta afirmação, estas categorias continuam atuais, precisando apenas acrescentar a emancipadora. Essas categorias demonstram uma avaliação está presente em todas as etapas do processo de ensino e aprendizagem, mas é importante compreendê-las e conhecê-las detalhadamente para que se possa escolher a mais adequada ao objetivo a ser alcançado.

\subsubsection{Avaliação Diagnóstica}

Pode-se dizer que avaliação diagnóstica é conhecer a realidade através da observação, do diálogo e do desenvolvimento de estratégias que possam caracterizar os espaços utilizados, os indivíduos que fazem parte da ação e as condições de aprendizagem. Ela tem dois objetivos segundo Blaya (2004):

A Avaliação Diagnóstica tem dois objetivos básicos: identificar as competências do aluno e adequar o aluno num grupo ou nível de aprendizagem. No entanto, os dados fornecidos pela avaliação diagnóstica não devem ser tomados como um "rótulo" que se cola sempre ao aluno, mas sim como um conjunto de indicações a partir do qual o aluno possa conseguir um processo de aprendizagem (BLAYA, 2004). 
Este tipo de avaliação surgiu da ideia de promoção continuada que foi instituída através da LDB de 1996. É importante lembrar que a avaliação diagnóstica alimenta e dá subsídios para as avaliações formativa e somativa, mas é relevante lembra que o diagnóstico não se limita ao início dos trabalhos a serem desenvolvidos com o aluno, pois pode e deve ser usada no início de cada atividade de ensino ou mesmo diante de um novo conceito a ser trabalhado, uma nova experiência a ser construída.

\subsubsection{Avaliação Somativa}

A avaliação somativa, é considerada como uma das mais utilizadas da metodologia tradicional e instrucionista, que hoje em dia não tem sido vista com bons olhos por diversos educadores. Apesar de toda a rejeição que ela recebe não deixa de ser um instrumento de estudo por sua importância como instrumento de avaliação, que certamente ainda tem lugar cativo em alguns projetos de ensino e em cursos de todos os níveis (MIRAS e SOLE, 1996).

A característica principal da avaliação somativa é o julgamento que se faz do aluno, professor e currículo sob o ponto de vista da eficiência da aprendizagem ou ensino, após o desenvolvimento deste processo. Seus resultados são apresentados em forma nota ou um escore total, com referência a normas de atribuição de outras notas que compõem o escore final, enfatizando prioritariamente os comportamentos da área cognitiva. Em alguns conteúdos, julgamse também os comportamentos psicomotores e ocasionalmente, os afetivos. O erro deste tipo de avaliação está no fato de ela ocorrer apenas no final do processo, quando já é muito tarde ao aluno que apresentou dificuldades no decorrer de todo o processo, alcançar os objetivos propostos e procurar mudar as estratégias de aprendizagem (SANT’ANNA, 2002).

\subsubsection{Avaliação Formativa ou Continuada}

A Avaliação Formativa ou continuada é a forma de avaliar em que a coleta de dados é a sua preocupação central. Esta coleta tem como objetivo a reorientação do processo ensinoaprendizagem e atua como um norteador para este processo. Ela não é expressa através de uma nota, mas sim por meio de comentários, observações e os mais diversos mecanismos a serem utilizados dentro de uma instituição escolar. É ela quem vai promover a formação contínua e sistemática do aluno durante todo o processo educacional.

Para Haydt (2002):

A avaliação formativa permite constatar se os alunos estão, de fato, atingindo os objetivos pretendidos, verificando a compatibilidade entre tais objetivos e os resultados efetivamente alcançados durante o desenvolvimento das atividades propostas. Representa o principal meio através do qual o estudante passa a conhecer seus erros e acertos, assim, maior estímulo para um estudo sistemático dos conteúdos (HAYDT, 2002, p. 17).

Este tipo de avaliação sobressai-se às demais por causa da regulação das atuações pedagógicas interessando-se, mais pelos procedimentos adotados e não apenas nos resultados. Ela procura a regulação pedagógica, criando a gestão dos erros e a estruturação dos êxitos. 


\subsubsection{Avaliação Emancipadora}

A Avaliação Emancipadora é caracterizada pelo processo de descrição, análise e crítica de uma realidade, com a intenção de transformála. Destina-se à avaliação de programas educacionais ou sociais. Granzotto (2003) afirma que:

O compromisso principal desta avaliação é o de fazer com que as pessoas direta ou indiretamente envolvidas em uma ação educacional escrevam a sua própria história e gerem as suas próprias alternativas de ação (GRANZOTTO, 2003, p. 17).

Esta avaliação aparece como uma forma pedagógica e filosófica de se posicionar dialeticamente num processo crítico. Vem favorecer a construção de um saber que se importa e compromete com a sociedade que está sendo construído todo o processo.

$\mathrm{Na}$ avaliação emancipadora, o professor deve recorrer a instrumentos de auto-avaliação e co-avaliação para que possa desenvolver o senso de autocrítica e melhorar o autodesenvolvimento do aluno. Como resultado, esta avaliação é expressa por meio de relatórios qualitativos sobre o aluno e todo o seu desenvolvimento global no decorrer do processo.

É importante salientar que a avaliação deve ser um momento privilegiado para a relação professor-aluno, pois é extremamente desagradável ao aluno, ao curso em desenvolvimento e ao professor descobrir, ao ser avaliado, que está muito longe dos objetivos traçados e que seus esforços em atingi-los resultaram em fracasso.

\section{A AVAliaçÃo FORMATIVA OU CONTINUADA NA UNIVERSIDADE DE ODONTOLOGIA: UMA POSSIBILIDADE?}

A avaliação não é um fato isolado como muitos educadores pensam, mas acontece através de uma prática pedagógica coerente e organizada, em conformidade com o perfil do professor e com o aluno que se quer formar, atenta aos objetivos desta formação e fazendo um elo de ligação entre o ensino e a aprendizagem. A avaliação faz parte de todo este processo e não pode ser isolada.

Alguns professores dos cursos de Odontologia têm demonstrado esta preocupação com a aprendizagem, ou não de seus alunos, mas outros apenas vêem a sua função como a de transmitir o conteúdo, a aprendizagem é vista como reprodução desses conteúdos transmitidos e a avaliação, apenas como uma devolução, uma via de memorização desses conteúdos, sem a preocupação com as consequências pedagógicas e profissionais que essa postura transmite.

Segundo Hadji (2001):

... porém sempre com referência a uma relação ideal entre um aluno ideal e o mesmo objeto de saber.

Em outras palavras: o avaliador tem sempre um pé fora do presente do ato de avaliação. Avaliar não consiste, pois, simplesmente, em medir esse desempenho, mas em dizer em que medida ele é adequado, ou não, ao desempenho que se podia esperar desse aluno. Em nome de quê? Do modelo ideal que orienta a leitura da realidade e que preside ao levantamento de indícios. Será em função desse modelo que se manifestarão expectativas precisas acerca do aluno (HADJI, 2001, p. 45).

Assim, entende-se que avaliar não deve ser feito ao final de um conteúdo, mas durante o processo inteiro, desde a introdução, 
continuando no desenvolvimento e também na conclusão, respeitando as diferenças individuais existentes na sala de aula, além de se ater à essência do conhecimento tratado. Com isso, o professor pode adquirir parâmetros, buscando formas diferentes de propor novos desafios, para que o aluno reflita e possa assim, recriar suas soluções, construir seus fatos e seus conhecimentos.

A avaliação no ensino superior, principalmente nos cursos de Odontologia, precisa de mudanças urgentes, onde o aluno possa decidir juntamente com o professor qual a melhor estratégia para que possa realmente aprender e não apenas acumular conhecimento decorativo. Decidir o que é importante ser avaliado e o porque de utilizar certos instrumentos fazem parte de uma avaliação formativa ou continuada, que é o propósito deste trabalho.

Hadji (2001) demonstra, em sua opinião a mesma coisa ao afirmar que:

\begin{abstract}
... acentuando-a, organizando-a, instrumentalizando-a, para auxiliar o aluno a "apreendê-la", a dominá-la, e talvez a integrá-la de modo tal que possa fazer parte desse autocontrole quase automático, que faz a grande força do especialista. Do novato ao especialista, é necessária, sem dúvida, a passagem por fases automatizadas, e trabalhadas, de avaliação instrumentalizada com vocação formativa (HADJI, 2001, p. 130).
\end{abstract}

Em sua pesquisa no curso universitário, com alunos de 05 universidades de Odontologia, Hoffmann (1993) apontou as concepções apresentadas pelos professores que eram resistentes a uma avaliação continuada e mostra os caminhos para reflexão:

a) alunos desinteressados e desatentos: $\mathrm{O}$ educador deve ter o compromisso de se aproximar deles. Na avaliação continuada, o professor despertaria, para esta relação dialógica da avaliação, na busca de alternativas para estabelecer uma aproximação e descobriria os diferentes modos de pensar do aluno.

b) tempo e disponibilidade: problemas do processo - a avaliação continuada demonstra uma ação reflexiva e desafiadora, onde o educador deve contribuir, elucidar e favorecer a troca de ideias entre ele e seus.

c) o diálogo professor/aluno: o diálogo entendido a partir da relação epistemológica deve ser feito não apenas através da conversa, mas de todas as maneiras a atingir o aluno.

d) acompanhamento individualizado: o diálogo é entendido como leitura curiosa e investigativa por parte do professor.

Descobrir uma avaliação contínua é um desafio para uma formação profissional competente e atual. Através de experiências de avaliação continuada é possível se obter um reestudo do currículo, para as possíveis adequações e reflexões quanto às necessidades dos alunos.

Nesta perspectiva, avaliação continuada é uma nova postura de vida e seus fundamentos ultrapassam os limites dos estudos sobre as teorias de avaliação, além de pedirem um aprofundamento maior nas teorias do conhecimento, e também estudos nas áreas específicas de trabalho do professor (HOFFMAN, 1993). 
A ação avaliativa continuada se desenvolve em prol do estudante e acontece através da proximidade entre quem educa e quem é educado. Ao querer conhecer a quem educa e conhecendo-o, o professor descobrirá quem ele é. O conhecimento das possibilidades que os educandos podem ter podem ser instrumentos que criarão oportunidades desafiadoras e maravilhosas.

Henzi et al. (2007), realizaram uma pesquisa, em 20 universidades americanas, sobre a percepção dos alunos em relação aos pontos fortes e fracos do curriculum das escolas de Odontologia, através de um questionário. Com relação ao processo avaliativo os alunos relataram que são utilizados testes de múltipla escolha que apenas indicam a capacidade de memorização do conteúdo e que, quase sempre, são esquecidos após as provas. Relataram ainda que, apesar dos professores serem altamente graduados, suas aulas não apresentam desafios intelectuais e não incentivam a integração de conteúdos e nem a capacidade criativa e interpretativa dos alunos.

Chaves (2006) destaca várias possibilidades para se obter uma avaliação da aprendizagem do ensino superior em Odontologia, que podem trazer contribuições para a transformação, onde os professores universitários poderão discutir e criar alternativas a partir do contexto de sala de aula e de conteúdo, uma vez que a mudança dessas práticas não se dá de fora para dentro, mas, a partir dos interesses e necessidades de seus protagonistas:

- atentar principalmente para os processos e não só para os resultados;

- dar possibilidades aos protagonistas de se expressarem e de se avaliarem;
- utilizar procedimentos e instrumentos variados para avaliar a aprendizagem;

- intervir, com base nas informações obtidas via avaliação, em favor da superação das dificuldades detectadas;

- configurar a avaliação a serviço da aprendizagem, como estímulo aos avaliados e não como ameaça;

- contextualizar e integrar a avaliação ao processo ensino - aprendizagem;

- definir as regras do jogo avaliativo desde o início do processo;

- difundir as informações e trabalhar os resultados, visando retroalimentar o processo; realizar meta - avaliação, paralela aos processos de avaliação propriamente ditos; e - considerar e respeitar as diferenças e as dificuldades manifestadas em sala de aula (CHAVES, 2006, p. 11).

Mudanças mais significativas em relação à avaliação da aprendizagem do aluno no ensino superior não acontecerão através de ações individualizadas ou isoladas, sem o vínculo com o projeto pedagógico curricular compartilhado e participativo. Este projeto deve favorecer a reflexão comunitária, sem desconsiderar o papel que o contexto social tem sobre a função que a universidade exerce na formação profissional de seus alunos e dos riscos de, através da avaliação, legitimar processos de exclusão e discriminação na sala de aula universitária.

Refletir sobre esta prática é andar por um caminho muito promissor, onde a integração entre os objetivos do ensino e a formação profissional atuará em favor do aluno universitário de Odontologia, favorecendo sua aprendizagem.

Mudar as concepções e as práticas avaliativas não é deixar de avaliar, nem afrouxar. Ao contrário, é ser mais exigente e avaliar muito mais. Além disso, não podemos mais avaliar apenas o aluno, pois todo o sistema faz parte do processo, inclusive o nosso trabalho como professores. Avaliar a aprendizagem de nossos 
alunos, por mais complexo que possa parecer, é possível e necessário. Não haverá transformação sem ações concretas, mesmo que pareçam pequenas (MENDES, 2005).

Adotando uma avaliação continuada em um processo educativo, é importante destacar que uma proposta só se traduz em prática pedagógica, se o professor estiver ligado a ela emocional e intelectualmente. Toda a proposta de mudança deve ser precedida por momentos de reflexão junto aos professores, para que analisem as razões e a validade dessa proposta e, assim, possam conseguir a adesão necessária para uma inovação.

Por ser o processo que dá uma direção ao ensino e à aprendizagem, a avaliação deve permitir uma leitura do que foi realizado, a partir dela, para continuar ou mudar o caminho a ser seguido. A avaliação proporciona uma orientação adequada, garantindo que se tenha o controle do processo, de modo que sua proposta de trabalho, seu planejamento seja transmitido e seus alunos possam ficar satisfeitos com o que realmente aprenderam.

\section{CONSIDERAÇÕES FINAIS}

Em síntese, a avaliação deve buscar a comprovação da aprendizagem do aluno, mas, sobretudo, o porquê dessa aprendizagem não ter sido realizada. Um instrumento não faz milagres; ele fornece elementos para a análise e interpretação dos resultados, mas precisa ser usado em nome de uma avaliação que, além do julgamento sobre o aluno, interfira na realidade educacional, transformando-a para melhor (DEPRESBITERIS, 2007).

A avaliação deve procurar no aluno o que ele realmente aprendeu, para que se saiba o que não conseguiu assimilar e assim, solucionar o problema de maneira tranquila. Cabe ao educador interpretar o instrumento utilizado por ele de maneira democrática e justa.

Elaborar instrumentos de forma diferenciada, relacionadas ao dia a dia do aluno, cobrar conhecimentos obtidos de forma objetiva, explorar a interpretação, a compreensão e a síntese do que foi apreendido, podem trazer dificuldades ao aluno no domínio do conteúdo.

A avaliação deve estar centrada na aprendizagem do aluno de maneira direta e imediata, observando o dia a dia do processo de aprendizagem e não momentos separados e isolados. Neste sentido, ela é contínua, embora nem toda avaliação contínua seja formativa, já que nem todas possuem a finalidade de contribuir para a progressão da aprendizagem. Uma avaliação voltada para o erro do aluno não construirá uma perspectiva de sucesso escolar e não efetivará a aprendizagem, principalmente num curso onde a prática e a experiência é de grande valia, como no curso de Odontologia.

A avaliação não é o único problema que enfrentamos. Uma nova prática avaliativa requer, necessariamente, novas práticas metodológicas. Isso significa que não basta mudar a forma de avaliar se não mudarmos as formas de organização de nossas aulas. A metodologia precisa ser diversificada, problematizadora e ter como princípio o diálogo. Se o aluno não aprendeu de uma forma, é preciso tentar outras formas até que ele aprenda. Para isso precisamos ter coragem de atrasar o programa e atender às necessidades de nossos alunos. Isso quer dizer que precisamos retomar, rever, re-enfocar, replanejar, alterar o ritmo, 
buscar novas estratégias de abordagem (VASCONCELLOS, 1995).

Paro (2003), é contrário a uma avaliação baseada no fracasso escolar, que sempre dominou o sistema educacional, principalmente o sistema educacional universitário e especialmente, no curso de Odontologia, e afirma que a avaliação deve fazer parte da vida em sociedade permanentemente. Entende que a avaliação deve ser dinâmica, com interações de diálogos permanentes entre todos os envolvidos.

Enfim, o que se deve ter certeza é que a avaliação não pode ser excludente, mas deve favorecer a capacidade de cada aluno de tomar posse de seus conhecimentos culturais, sociais, científicos e tecnológicos, num espaço de democracia, onde cada indivíduo poderá construir sua trajetória histórica.

A avaliação não começa e nem termina dentro da sala de aula, mas transcende estes limites. A que mais se enquadra neste processo é aquela em que o aluno sai do papel passivo e ocupa um papel mais ativo, juntamente com o professor. Deve ser o professor o grande regente desta orquestra, organizando os instrumentos a serem tocados, juntamente com os músicos, seus alunos, fazendo-os grandes musicistas, de sucesso aparente, podendo assim, transformar as suas realidades e a realidade educacional de nosso país.

\section{REFERÊNCIAS}

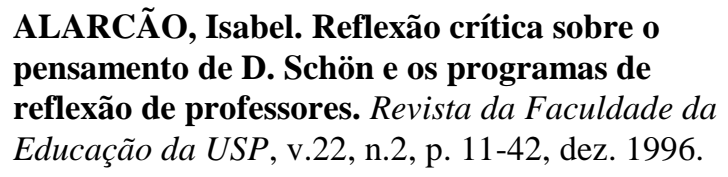

BERBEL, Neusi A. N. et al. Avaliação da Aprendizagem no Ensino Superior. Um retrato em cinco dimensões, Londrina: Editora UEL, 2001. BLAYA, Carolina. Processo de Avaliação. Disponível em:

http://www.ufrgs.br/tramse/med/textos/2004_07_20_t ex.htm, 2004. Acessado em 21 de julho de 2010.

BLOOM, Benjamin et al. Taxonomy of Educational objectives. Hand Book I, Nova Iorque, 1956.

BROADFOOT, P. Education, assessment and society: A sociological analysis. Buckingham: Open University, 1996.

CAMARGO, Alzira Leite Carvalhaes. O discurso sobre a avaliação escolar do ponto de vista do aluno. Campinas, Tese (Doutorado) - Faculdade de Educação, Universidade Estadual de Campinas, 1996.

CHAVES, S. M. Avaliação da Aprendizagem no Ensino Superior: Realidade, Complexidade e Possibilidades. Goiânia: Ed.UFG, GT:Didática, n.04, 2006.

COLL, César. Psicologia e currículo. São Paulo: Ática, 1999.

César et al. $O$ construtivismo na sala de aula. Novas perspectivas para a ação pedagógica (trad. do espanhol), Porto, Edições Asa, 224 p 2001.

CORTESÃO, Luiza. Avaliação Formativa: que desafios? Coleção Cadernos Pedagógicos, 2.ed. Lisboa: Edições Asa, 1993.

DAMIS, D.T. Didática: suas relações, seus pensamentos. In: VEIGA I.P. de A. (coord.). Repensando a didática. 11.ed. Campinas: Papirus, 1996. p.13-40.

DEMO, P. Ser professor é cuidar que o aluno aprenda. Porto Alegre:Mediação, 2004.

DEPRESBITERIS, L. Instrumentos de avaliação: a necessidade de conjugar técnica e procedimentos éticos. In: Revista Aprendizagem, Pinhais: Ed. Melo, ano $1, \mathrm{n}^{\mathrm{o}} .1$ - jul/ago, 2007.

ESTEBAN, M.T. (Org) Avaliação: uma prática em busca de novos sentidos. Rio de Janeiro: DP\& A,1999.

FERNANDES, D. Avaliação das Aprendizagens: Desafios às Teorias, Práticas e Políticas. Lisboa: Texto Editora, 2005.

FIRME, T. P. Avaliação: tendências e tendenciosidades. Ensaio: Avaliação e políticas 
públicas em educação. Rio de Janeiro, v. 2, n. 1, p. 57-61, out./dez., 1994.

FREIRE, Madalena. A paixão de conhecer o mundo. R. J.: Paz e Terra, 1986.

GRANZOTTO Carina M. N. Os caminhos para avaliar: qual seguir? Revista do Centro de Ciências Humanas e Comunicação da Universidade de Caxias do Sul. $1^{\circ}$ semestre, p. 15-20, 2003.

HADJI, Charles. A avaliação desmistificada. Porto Alegre: ArtMed, 2001.

HAYDT, Regina Célia Cazaux. Avaliação do Processo Ensino-Apredizagem, São Paulo: Editora Ática, 6 ${ }^{\mathrm{a}}$ Ed., 2002.

HENZI, D.; DAVIS, E.; JASINEVICIUS, R., HENDRICSON, W. In the student's words: What are the strengths and weaknesses of the Dental school curriculum?. Journal of Dental Education, v.71, n.5, p.632-645, 2007.

HOFFMANN, J. Avaliação mediadora. Uma prática em construção da pré-escola à universidade. Porto Alegre: Educação \& Realidade, 1993.

KRAEMER, Maria Elisabeth Pereira. Avaliação da Aprendizagem como Processo Construtivo de um Novo Fazer , 2005. Disponível em

http://www.gestiopolis.com/Canales4/ger/avaliacao.ht m, acessado em 20 jul 2010.

LUCKESI, C. C. Avaliação da aprendizagem escolar: apontamentos sobre a pedagogia do exame. Tec. Educ. v.20,n.101, p.82 - 86, 1991.

LUCKESI, C. A avaliação da aprendizagem escolar. São Paulo: Cortez, 1995.

MELLO, M. H., QUINTELLA H. L. e MELLO, J. C. Avaliação do Desempenho de Alunos Considerando Classificaçãoes Obtidas e Opiniões dos Docentes. Investigação Operacional, 24, p. 187 196, 2004.

MENDES, OLENIR MARIA. Avaliação formativa no ensino superior: reflexões e alternativas possíveis. In: VEIGA, I. P, A e NAVES, M. L. P. (orgs). Currículo e avaliação na educação superior. Araraquara - SP: Junqueira \& Marin. 2005, p. 175197.

MÉNDEZ, Juan Manuel Álvarez. Avaliar para conhecer. Examinar para excluir. ed. Porto Alegre Artmed Editora, 2002.

MIRAS, M. e SOLÉ, I. A Evolução da Aprendizagem e a Evolução do Processo de Ensino e Aprendizagem in COLL, C., PALACIOS, J.,
MARCHESI, A. Desenvolvimento psicológico e educação: psicologia da educação. Porto Alegre: Artes Médicas, 1996.

NEVO, David. The conceptualization of educational evaluation: An analytical review of the literature. In: HOUSE, Ernest R. (editor). New directions in educational evaluation. Philadelphia, USA: The Falmer Press, 1986.

PARO, Vitor H. Reprovação escolar: renúncia à educação. $2^{a}$ ed. São Paulo: Xamã, 168 p., 2003.

SANT'ANNA, Ilza M. Por que avaliar? Como avaliar? 9 ed. Petrópolis:Vozes, 2002.

SILVA, Rinalva Cassiano (org) Educação para o século XXI - dilemas e perspectivas. Piracicaba: Ed. UNIMEP, 1999.

TAILLE, Yves de La et al. Grandes Pensadores em educação-O desafio da Aprendizagem, da Formação Moral e da Avaliação. $3^{\mathrm{a}}$ Ed., S.P:Mediação, 2002.

VASCONCELLOS, CELSO DOS S. Avaliação: concepção dialética-libertadora do processo de avaliação escolar. São Paulo: Libertad, 1995.

VIANNA, Heraldo M. Avaliação Educacional: Teoria, Planejamento e Modelos, São Paulo, IBASA, 2000.

Maria Cláudia Cardoso de Brito

Mestre em Clínicas Odontológicas pela Pontifícia Universidade Católica de Minas Gerais (PUC/MG) Graduação em Odontologia pela Pontifícia Universidade Católica de Minas Gerais(PUC/MG). Professora da Universidade Vale do Rio Verde (UninCor).

Flávia Moysés Costa de Grajeda

Mestre em Materiais Dentários pela Universidade Federal de Minas Gerais (UFMG) Graduação em Odontologia pela Pontifícia Universidade Católica de Minas Gerais(PUC/MG). Professora da Universidade Vale do Rio Verde (UninCor).

Lílian Juri Rezende de Lacerda

Acadêmica da Universidade Vale do Rio Verde (UninCor)

Carolina Freitas Lage

Mestre e Doutora pela Universidade Federal de Minas Gerais (UFMG). Graduação em Odontologia pela Pontifícia Universidade Católica de Minas 
Gerais (PUC/MG). Professora da Universidade Vale do Rio Verde (UninCor).

Túlio César Modesto

Mestre em Endodontia pela Universidade Federal de Minas Gerais (UFMG). Graduação em Odontologia pela Universidade Federal de Minas Gerais (UFMG)

Professor da Universidade Vale do Rio Verde (UninCor). 